\title{
A qualitative study exploring why people do not participate in cardiac rehabilitation and coronary heart disease self-help groups, and their rehabilitation experience without these resources
}

\author{
Angela Mary Jackson ${ }^{1}$, Brian McKinstry ${ }^{2}$, Susan Gregory ${ }^{3}$ and Amanda Amos ${ }^{4}$ \\ ${ }^{1}$ The Research Unit in Health, Behaviour and Change, The University of Edinburgh, Edinburgh, UK \\ ${ }^{2}$ Reader, Department of Primary Care Research, Centre for Population Health Sciences, University of Edinburgh, UK \\ ${ }^{3}$ Research Fellow (retired), Centre for Population Health Sciences, University of Edinburgh, UK \\ ${ }^{4}$ Professor, Department of Health Promotion, Centre for Population Health Sciences, University of Edinburgh, UK
}

\begin{abstract}
Background: Secondary prevention and self-management of coronary heart disease (CHD) are of major importance to people who survive myocardial infarction (MI). This can be facilitated by cardiac rehabilitation (CR; the formal health service programme) and informal CHD self-help groups. Non-participation is an important issue, yet it is poorly understood. Rehabilitation difficulties and prevention challenges have been identified among people following $\mathrm{MI}$, but the particular experience and perspective of CR and CHD group non-participants are largely unknown. Aim: The study aimed to understand non-participation in CR and CHD self-help groups from the perspectives of the non-participants and to provide insight into their experience and that of their 'significant others' in rehabilitating in the absence of these resources. Methods: In-depth interviews were conducted with 27 people who had not participated in either hospital-based CR or a CHD group, 6-14 months post-MI, and 17 'significant others' in Lothian, Scotland. Findings: Factors influencing non-participation fell into three broad themes 'No need/no point', 'Not worth it', and 'Not possible'. In the latter two categories, non-participation in these resources was often considered a 'missed opportunity' and needs had remained unmet. Shifts between categories could occur over time. Non-participation was linked to rehabilitation difficulties for some people and family members. Recommendations to enhance post-MI support are made.
\end{abstract}

Keywords: CHD; CR rehabilitation; non-participation; secondary prevention; self-help groups

Received 8 October 2010; accepted 21 June 2011; first published online 8 August 2011

\section{Introduction}

More people are surviving myocardial infarction (MI) and living with coronary heart disease

Correspondence to: Dr Angela Mary Jackson, Programme Manager (Rural and Urban Communities), Scottish Ambulance Service Headquarters, Tipperlinn Road, Edinburgh, EH105UU, UK. Email: angelajackson2@nhs.net
(CHD) as a chronic condition (Petersen et al., 2003; Mackay et al., 2004). Consequently, secondary prevention and self-management have assumed major importance (Mackay et al., 2004; Scottish Government, 2007). Achieving and maintaining risk-reducing lifestyle changes can be difficult even after support interventions (Ebrahim and DaveySmith, 1997; Campbell et al., 1998), and such support provision is limited (Clark et al., 2005). 
Some patients fail to access or receive the recommended support after their infarct (Clark et al., 2002; Dalal and Evans, 2003). Problems in the secondary-primary care transition mean some people 'slip through the net', with negative consequences for rehabilitation and secondary prevention (Clark et al., 2005). Previous research has highlighted difficulties accessing and receiving sufficient support and advice generally (Roebuck et al., 2001), and specifically from General Practitioners (Richards and Coulter, 2007), and reticence in seeking support (Gregory et al., 2005).

Two primary resources in the United Kingdom specifically support post-MI rehabilitation and readjustment: cardiac rehabilitation (CR) programmes are a 'formal', structured National Health Service (NHS) health service, generally delivered in a hospital setting. Reviews indicate that 'comprehensive' $\mathrm{CR}^{1}$ can aid physical recovery, improve psycho-social well-being, reduce clinical and lifestyle-related risk factors, and increase participant knowledge (Thompson and Lewin, 2000; Dinnes et al., 1999), which may in turn contribute to reducing mortality and morbidity (Bethell et al., 2007). CHD groups are 'informal' communitybased, non-NHS groups for community members with CHD that manifest characteristics of self-help initiatives. The evidence base is less developed than for formal interventions, but studies suggest that support - particularly emotional - is important, as are enhanced psychological and emotional wellbeing, increased condition-related knowledge, support for secondary-prevention lifestyle changes, and recovery and maintenance of lifestyle activities (Jackson et al., 2009).

Nevertheless, many people do not use either resource. Generally, less than $50 \%$ of referred people in the United Kingdom attend CR (Beswick et al., 2004; Bethell et al., 2007), and only a minority attend CHD groups (Davison et al., 2000; Bostock et al., 2007). Home-based models of CR have been developed to provide an alternative delivery model and address barriers to attending a hospital-based programme and are found to be effective (Taylor et al., 2010). The 'Heart Manual' is one example,

\footnotetext{
${ }^{1}$ Comprehensive cardiac rehabilitation consists of exercise training, behavioural change, education, and psychological support to facilitate a return to normal living and to encourage patients to make lifestyle changes in order to prevent further events [9].
}

developed and used in Lothian, where this study was based. This resource comprises an information manual and relaxation CDs, and may be accompanied by brief nurse advice visits, and is recommended for the early post-discharge period by Scottish guidelines (SIGN, 2002). Wingham et al. (2006) found that home-based CR appealed to some patients who disliked groups, preferred homebased self-management, and were self-disciplined. However, their study was based on pre-discharge intentions rather than actual participation/nonparticipation. Broader health research indicates that intentions may not be borne out by actual decisions and behaviour (Blaxter, 2004; Jepson et al., 2005); meanwhile, a small-scale study of CR non-participation indicated that in the early postdischarge period people's intentions could be influenced by their post-discharge circumstances (Hagan et al., 2007). Furthermore, the potential for a person's perceptions of the value of rehabilitation resources to evolve over the course of their rehabilitation has not been investigated.

CHD group non-participation is poorly understood and the perspectives of non-participants themselves have been neglected. These self-help groups operate in a different setting and format to both hospital and home-based CR. Moreover, they are based on a 'social model' of health and illness: collective support to help individuals learn how best to live with their condition; and holistic, catering for social, emotional, and practical needs as well as considering physical health. This contrasts with CR, based on the 'medical model', which emphasises adherence to standardised treatments and procedures to control the clinical manifestations of a condition. Participation motivations may therefore differ, while the possible interaction between participation and non-participation in these formal and informal resources also remains to be examined. These issues suggest the need for a study of both CR and CHD group non-participants' perspectives and experiences at a later stage in their rehabilitation.

Furthermore, the experience of $\mathrm{CR}$ and CHD group non-participants and those of family and friends informally supporting their rehabilitation remain essentially unknown. Important common themes in the literature concerning people with CHD generally or other chronic conditions must be considered provisional regarding non-participants. Living with, and managing CHD and other 
chronic conditions, is challenging and for some people and families life-altering (Charlton and Barrow, 2002; Clark, 2003). Impacts extend beyond the body into all aspects of daily life and can fundamentally change the way people see themselves and are seen (James and Hockey, 2006; Wheatley, 2006). The extent that the experiences and perspectives identified among the wider CHD population are reflected in or dissimilar to $\mathrm{CR}$ and $\mathrm{CHD}$ group non-participants requires investigation. People generally draw upon a range of formal, semi-formal, and informal resources to manage illness, thus understanding how nonparticipation relates to use and non-use of wider resources is important, particularly the perspectives and experiences of the 'significant others' involved in supporting non-participants.

This study explored reasons for CR and CHD group non-use and experiences of recovery without these resources from the perspectives of people who had experienced infarct and their 'significant others'.

\section{Methods}

We sent a letter indicating our interest in people's rehabilitation experiences after MI along with a brief questionnaire to all patients who were discharged from hospital in Lothian (Central Scotland) in the previous 6-14 months. The questionnaire asked about attendance at CR or CHD groups and for brief demographic and cardiac history information, and also asked about willingness to be interviewed and to nominate a 'significant other' for interview. We constructed a sampling frame to select a 'maximum variation' sample of people who indicated they were willing to be interviewed (Sandelowski, 1995). Recruitment proceeded until the sampling frame was complete. Selection criteria were degree of nonparticipation (CHD group non-participation; CR non-participation; attended neither; attended both), gender, age, geographical area, and ethnicity.

In-depth interviews were conducted by one of the authors (AJ) in interviewees' homes, using a topic guide of key themes identified from the

\footnotetext{
2 'Significant others' is the collective term used for close family members or friends who played a significant role in the life of the post-MI interviewees.
}

literature and discussions with practitioners. Interviews lasted on average one hour and were recorded and transcribed, with interviewees accorded pseudonyms to protect confidentiality. Detailed field notes were also made following each interview.

When approached for interview, interviewees who had experienced MI were requested to identify and invite a 'significant other' (eg, a spouse, son, daughter, or friend) to be interviewed. Data collection was complete when all authors agreed that saturation of data appeared to have been achieved. A 'grounded theory'based analytical approach was used to prioritise interviewees' perspectives and experiences. Stage one was 'immersion' in the data to identify themes (Pope and Mays, 2000; Ziebland and McPherson, 2006) through field notes, transcribing and editing interviews, reading and re-reading interviews, and producing interviewee vignettes. Emergent themes were prioritised, although themes reflecting the research aims, such as reasons for non-participation, were additionally sought (Seale and Kelly, 1998). The data were then coded to develop themes and sub-themes (Ziebland and McPherson, 2006). All transcripts were read by at least two of the authors and coding was agreed.

\section{Ethical approval}

The area NHS Ethics Committee approved the study methodology (06/S1103/13).

\section{Results}

One hundred and sixty-three people who had sustained an MI were approached. Seventy-four (45.4\%) completed screening questionnaires and $53(32.5 \%)$ consented to be interviewed. In-depth interviews were undertaken with 27 people who had had an MI, and 17 'significant others' (total $n=44) ; 34$ interviews were single and five paired. See Table 1 and Table 2 for demographic details.

\section{Understanding non-participation}

Non-participation was grouped into three categories based on the non-participating person's attitude towards CR and CHD groups in relation to their circumstances, beliefs, and identity. 
Table 1 Demography of post-MI interviewees

\begin{tabular}{|c|c|}
\hline & $\begin{array}{l}\text { Number } \\
\text { (total } n=27 \text { ) }\end{array}$ \\
\hline \multicolumn{2}{|l|}{ Non-participation } \\
\hline Participated in CR but not a CHD group & 10 \\
\hline $\begin{array}{l}\text { Did not participate in either CR or a } \\
\text { CHD group }\end{array}$ & 17 \\
\hline \multicolumn{2}{|l|}{ District } \\
\hline West & 13 \\
\hline Central & 10 \\
\hline East & 2 \\
\hline Mid & 2 \\
\hline \multicolumn{2}{|l|}{ Gender } \\
\hline Men & 17 \\
\hline Women & 10 \\
\hline \multicolumn{2}{|l|}{ Age groups } \\
\hline $30 \mathrm{~s}$ & 0 \\
\hline $40 \mathrm{~s}$ & 4 \\
\hline $50 s$ & 8 \\
\hline $60 \mathrm{~s}$ & 5 \\
\hline $70 \mathrm{~s}$ & 7 \\
\hline $80 \mathrm{~s}$ & 3 \\
\hline \multicolumn{2}{|l|}{ Ethnicity } \\
\hline 'White' Scottish & 25 \\
\hline 'White' Irish & 1 \\
\hline Indian & 1 \\
\hline \multicolumn{2}{|l|}{ Cardiac history } \\
\hline No diagnosed pre-MI CHD & 17 \\
\hline Pre-MI hypertension & 5 \\
\hline Pre-MI angina & 5 \\
\hline Pre-MI cardiac surgery & 0 \\
\hline \multicolumn{2}{|l|}{ Co-morbidity } \\
\hline No concurrent condition & 17 \\
\hline One concurrent condition & 5 \\
\hline Multiple concurrent conditions & 5 \\
\hline
\end{tabular}

$\mathrm{MI}=$ myocardial infarction; $\mathrm{CR}=$ cardiac rehabilitation; $\mathrm{CHD}=$ coronary heart disease.

\section{Category one: 'no need/no point'}

For these people, there were strong negative influences that made them believe the resource would not be personally beneficial for their recovery. They identified additional barriers (eg, transport) and deterrents (eg, dislike of groups), or negative perceptions, yet personal benefit was pivotal. Almost all had been invited to $\mathrm{CR}$ and/or a CHD group and declined. The uninvited said they would not have attended even if they had been invited. The reasons related to their perceptions of their health and capacity to recover, firstly whether they were confident they could recover without using these resources. Some, but not all, of these people had been given the 'Heart Manual' home-based rehabilitation resource and
Table 2 Demography of significant other interviewees

\begin{tabular}{lc}
\hline Family members/friends & Number (total $n=17$ ) \\
\hline Relationship to post-MI person & 11 \\
Wife & 2 \\
Husband & 2 \\
Daughter & 1 \\
Son & 1 \\
Friend & \\
District & 9 \\
West & 5 \\
Central & 1 \\
East & 2 \\
Mid & \\
Gender & 4 \\
Men & 13 \\
Women & \\
Age groups & 1 \\
30s & 2 \\
40s & 5 \\
50s & 4 \\
60s & 4 \\
70s & 1 \\
80s & 16 \\
Ethnicity & 1 \\
White' Scottish & \\
Indian & \\
\hline Ml = myocardial infarction & \\
&
\end{tabular}

this had increased their confidence in recovery. On the other hand, some people believed that their age or co-morbidities limited their capacity to regain better health and that CR or a CHD group would make little difference. Rena was one example. After twenty years of CHD, two previous MIs and several current co-morbidities, she believed only a medical or surgical innovation could improve her health.

I mean, I know what I can do and I know what I can't do, and I don't need them to tell me... and what are they going to do? They can't... I've had, erm, stents in my heart... twice...

(Rena: 67, married, retired pre-MI)

Family members sometimes perceived value and regretted their relative's non-participation but had been reluctant to voice their concerns. Some accepted the apparent non-availability of a resource as a 'fait accompli'. Others were reluctant to undermine or challenge their relative's decision.

Primary Health Care Research \& Development 2012; 13: 30-41 


\section{Category two: 'not worth it'}

These people believed that CR and/or a CHD group could potentially be beneficial, primarily as a means to recovery but also as a way to demonstrate to others that they were positively occupied, while unable to conduct their usual activities and responsibilities. However, they also perceived negative factors that made participation difficult or unappealing, so declined to attend. Retrospectively, some thought CR might have helped with difficulties they later experienced and expressed regret. Some had received the 'Heart Manual'; however, certain needs remained unmet. Not all were invited to a CHD group, but like those who had declined an offer, they considered that their belief at the time when their physical symptoms were abating would have encouraged them to try to recover without this resource. Their spouses regretted their non-participation but had accepted their decisions out of support or empathy.

Several who had attended CR said going on to join a CHD group might have been beneficial, but had declined their invitation, citing difficulties including travel distance, work patterns, physical discomfort, and dependency. It appeared that the perceived benefits had not seemed as compelling as those that persuaded them to attend CR, while $\mathrm{CR}$ had encouraged them to feel as though they were able to manage independently. They all identified obstacles that strengthened the rationale for not participating, but overall it appeared that a CHD group was not perceived as appropriate for their needs at that stage of rehabilitation.

You just would be going doing the same exercises as you were getting... at [District hospital] in the Rehab like... just a continuation of that... And... once I started back [at] my work, and plus... the travel from here to Iddrington every Monday... Ten, twelve mile. An' then well, I mean, I didn't drive...

(Jim: 53, married, employed)

\section{Category three: 'not possible'}

These people strongly desired to attend CR and/or a CHD group. They believed the resource would benefit them, was appropriate to their needs, and had a suitable format, yet were impeded by one or more barriers. The primary barriers were not being informed or invited, and in the case of CHD groups, apparent non-availability. Other barriers related to practical circumstances, for example, travel, work hours, disability, but appeared less prominent than in the accounts of people in category two, with the implication these could have been surmounted. Patients and some family members were therefore denied the opportunity to use post-MI resources they believed would have assisted them. Most said they had not been invited, one was told his disability precluded participation, and another had apparently been referred only to a generic psychological service, instead of the CHDspecific support he wanted. All expressed frustration at the lack of rehabilitation support, including those who had received the 'Heart Manual', and all except one said they would also have been interested in attending a CHD group had one been available.

AJ: I know in some areas they've got... like cardiac groups, some of them do exercise, some of them do [other things]...

C: And they still meet even after they finish their rehab? See, there was nothing like that. I actually had thought about that, and I thought that would have been actually a good idea, where you could carry on, and...

AJ: It wasn't mentioned at rehab or by your doctor or anything?

C: No, nothing, nothing at all. I don't know whether they have anything like that here... (Colleen: 63, married, employed)

\section{Shifts between categories}

While interviewees' non-participation patterns generally appeared to fit one of the three categories, a number of interviewees shifted between categories in response to changes in circumstances, beliefs, and identity. The retrospective study design allowed interviewees to reflect on their 'recovery journey' and how their experiences and expectations changed over time. With hindsight, a person who had been invited or informed about CR and/or a CHD group in their early rehabilitation period, might, in the light of subsequent experiences reconsider their negative assessment of the resource's benefits or feasibility. 
For example, Linda declined both $\mathrm{CR}$ and a $\mathrm{CHD}$ group and illustrates a shift from category one (non-beneficial) to two (outweighed). She initially believed the resources were not personally necessary, believing that her condition was not serious, while she also preferred self-reliance. With hindsight, she believed her recovery might have been easier, and her smoking cessation attempts successful, if she had accepted this support.

I think if I'd went maybe four classes or something like that... just to talk and say, 'Well, did you feel like that?', you know... 'Cause I still feel like shite... You know 'Do you?', 'Am I doing something wrong?', Whereas you didn't have that... Yeh, in that way I would have liked that support...

(Linda: 45, partner, employed)

\section{Rehabilitation difficulties}

Interviewees' and family members' assessments of the recovery period varied considerably. There were people who believed successful progress towards recovery had been made, and that their recovery had been manageable. Yet, even they had encountered hurdles. Moreover, there were many whose experiences had been, or still were, extremely challenging, and struggled to manage. The findings suggest a link between CR and CHD group non-participation and absence of the types of support available through these and the rehabilitation difficulties experienced by some patients and their family members.

Low expectations, reticence about highlighting health service deficiencies, and reluctance to request support contributed to some people's non-participation and compounded the difficulties. In some cases, interviewees explicitly linked a problem to a service deficiency. Nevertheless, they avoided blaming staff and generally thought it was unreasonable or unfeasible for a service to meet all needs and demands. Some espoused values of self-reliance and stoicism, suggesting that people should 'get on with' problems themselves rather than expecting a service to help.

I suppose, it's maybe it's just that, you know? They've not got the resources... Do you know what I mean? And perhaps we're just having a good old moan and... I mean, I know the NHS is stretched, but sometimes it is quite frustrating because you don't know which direction to go in...

(Teresa: wife, 50s, employed)

Uncertainty about future health, risk of further MI, and the extent they could regain their former way of life caused widespread unease and anxiety among patients and families. For some, these gradually diminished, but others remained uncertain and anxious months later. People without CR and CHD group support and lacking alternative resources could be especially vulnerable. These unaddressed needs could damage emotional and psychological well-being and could undermine confidence and motivation to return to life activities and to undertake recommended lifestyle changes. Not knowing what to expect or not receiving follow-up could exacerbate these issues and leave them vulnerable and isolated.

He says there's no guarantees it won't happen, and then again there's no guarantees that it will happen. So, I'm living now with that thought. Is it going to be the day that I'm going doon the road and I... And I don't feel I'm ready for work at the moment, or that... I don't actually know what... what I could do physically... I'm not going to lie to you... it has changed my life completely. I'm a season-ticket holder and I give my tickets away half the time, because... if it is going to happen again, I'd like it to happen near home, if you know what I mean?

(Alec: 53, married, not returned to work)

Some interviewees who received follow-up support felt it had been too late, too brief, or had not addressed key needs, particularly regarding mental, emotional, and for some 'cognitive' issues. A number described severe problems requiring specialist treatment. Some regretted not attending $\mathrm{CR}$ and/or CHD groups, believing that they might have addressed these issues, or at least helped them cope. Several interviewees had been deterred by perceived judgmental staff attitudes regarding issues, for example, smoking or their motivation, and this could make them reluctant to use support resources. Lack of motivational support, into the medium and longer term, was also highlighted by people who experienced difficulties instigating or maintaining lifestyle changes.

Primary Health Care Research \& Development 2012; 13: 30-41 
Inadequate information meant many interviewees felt unable to make an informed choice about whether to attend CR or a CHD group. In the light of their rehabilitation difficulties, this represented a 'missed opportunity', as many explicitly identified. Some had received the 'Heart Manual', but others had not. This was often considered helpful; yet, some had struggled to digest the information or follow the recommended programme, while others identified questions and concerns that had not been addressed. This could cause misunderstandings, anxiety, misjudgements, and maladjustment. It could also fuel family members' uncertainty and anxiety, adversely affecting their mental and emotional health, family relationships, and their capacity to provide practical or emotional rehabilitation support.

Many interviewees identified a need for additional support with difficult emotions: uncertainty, anxiety, difficulty accepting the MI and its consequences, sadness, and guilt. Depression and 'mood swings' affected several interviewees after their MI, and some family members also experienced depression. Although the duration, extent, and impact of difficulties varied considerably, the inadequacy of available support was a common theme.

It [support] might have been maybe even about how you would be feeling after it... after the initial shock's away and the pain's away... How you would be feeling... The mood swings - I don't know if that's associated with a heart attack or not... Erm, they just put it down to... [concurrent health problem] and stress of the heart attack and what I came through... Aye. More support... instead of just getting flung a book.

(Gayle: 41, partner, parent, post-MI nonreturn to work)

Although some people had some degree of support, this could be inadequate to meet CHDspecific needs, while some were reluctant to seek help from family and friends. Some said that meeting others with a similar experience would help them come to terms with their condition.

Most people that I've heard of had a heart attack... have died. I've never known anyone my age to take a heart attack. So there's nobody that I can relate with, no-one that I can speak to... You know? 'What did you do?' and 'How did you cope with it?' You get the six week follow-up and after that all I've had is my appointments at the hospital. There's no... groups that you can go to, or no-one that you can go and talk to, apart from your own GP...

(Dot: 43, single parent, post-MI non-return

to work)

Wider life difficulties, for example, pre-existing relationship or psychological problems, financial insecurity, or family illness, could exacerbate psychological and emotional difficulties experienced. CR and CHD groups would be unable to provide the intensive support a small number of interviewees appeared to need, and for whom these resources would not be sufficient, feasible, or acceptable. Yet, for the greater number with less intensive needs, who were open to considering CR and CHD groups, these resources appeared capable of providing support and alleviating difficulties.

A major issue for three interviewees was the impact of difficulties they ascribed to 'brain damage' following cardiac arrest. Memory loss was most commonly mentioned and in severe cases rendered people unable to perform basic life functions. Difficulty in speaking and in understanding speech was also described. All three experienced ongoing difficulties many months after their MI, damaging their own and their families' mental and emotional health, relationships, and capacity to undertake everyday tasks. All said they would have valued CHD group support. A common difficulty was having the problems acknowledged and identified, and generally felt professionals had dismissed them as medically unproblematic or less important than their cardiac condition.

He gets irritable! Impatient... I mean, he's not bad, but it's... Okay, to begin with I made allowances for it, but, erm, as time goes on, as I say, I'll perhaps say to him... But I let him know, you know? 'Cut it out! That's not necessary.' And when he [husband] spoke to the doctor he had said, 'Oh yes, but I suppose you're saying the same about your wife...', which I thought, 'Well, that's not nice.' And like it was a joke. (Judy: wife, 60s)

Difficulties were encountered in various aspects of daily life, including financial matters, employment, 
domestic and caregiver responsibilities, the home environment, and travel. Some people received support from statutory services, employers, and family and friends that addressed or eased their problems. Yet, many said they had struggled and experienced further problems, such as stress and depression. Although the support required extended beyond the remit of CHD groups, some interviewees felt that advice and support from others coping with similar issues would have helped.

Some family members experienced stress and ill health from taking on their relative's former tasks or undertaking an intensive caring role without support, and this could eventually undermine their capacity to provide rehabilitation support.

But I don't have anybody that I can contact and say, 'Look, this is happening, I think we might need a bit of help, or I think Ray might need a bit of support.' You know? 'Is there anything that I can do?' And you get to the point where you sit down and you just think, well, this is what life's going to be like now, so obviously I've just got to deal with it. But sometimes it is very difficult to deal with, because what happens is when Ray's down, it drags me down... After... after so long of trying to stay up there, you get exhausted... So you just think, 'I've had enough and I can't cope with this anymore.

(Teresa: wife, 50s)

Accounts indicated that their difficulties might have been mitigated if they and their relative had received condition-related and emotional support through CR and/or a CHD group, or an alternative resource. Some were not offered formal assistance. Others declined support believing, often with incomplete information or misconceptions, that it was not appropriate to their needs and preferences.

\section{Limitations}

The views of responders in a study of nonparticipants may be untypical. However, the response rates were not dissimilar to average health questionnaire response rates (Asch et al., 1997), suggesting that not all non-participants are 'hard to reach'. Most responders had not participated either in CR or a CHD group, reflecting the literature indicating that a substantial proportion of people after their infarct do not use one or both of CR and CHD groups. The sample was large compared with most nonparticipant qualitative studies, enabling a diverse interviewee profile to be assembled. This addresses an important weakness of many previous nonparticipant studies (Thompson and de Bono, 1999; Jolliffe et al., 2001) and increases the likelihood that the findings reflect the themes and issues among non-participants and family members more widely.

Interviewing people eight to fifteen months after their MI enabled interviewees to reflect on how their experiences and expectations changed over time. However, Bury (1991) cautions that an interviewee's reflections and the 'piecing together' of events or thoughts that led to a particular outcome may present non-use as a more logical, considered, and conscious process than it was. Some interviewees might also have sought to justify their decisions and actions to themselves and the interviewer. Two measures were used to ensure the quality and integrity of the research. Reflexivity-acknowledging the factors that may have influenced the findings, for example, interviewees' perceptions of the interviewer, and the way the interviewer's health promotion background might have influenced their interpretation. This provides transparency to enable readers to evaluate the findings in this context and allows the researcher to check that their interpretations are convincing (Mason, 1996; Finlay, 2003). Secondly, all authors were involved in study planning, reading transcripts, and the analytical process, where critical discussion and reflection were encouraged.

\section{Discussion}

Previous studies have identified important benefits of CR (Jolliffe et al., 2001; Clark et al., 2005) and CHD groups (Gregory et al., 2006b; Bostock et al., 2007). Non-participant research suggests that non-attenders may be missing out (Hildingh and Fridlund, 2001; Cooper et al., 2002). This study found that for many interviewees non-use represented a 'missed opportunity' to aid rehabilitation, assist secondary prevention, and support families. 
Wiles and Kinmonth (2001) show that people's early optimism regarding recovery might be confounded and de-motivate rehabilitation efforts. Interviewing people later in their recovery period found that some had reassessed their nonparticipation stance due to changes in their circumstances and beliefs, and then viewed a resource as more positive or viable. According with Wingham et al. (2006), this study found that some people may set out with the intention of being self-reliant, may prefer the convenience of a home-based resource, and may not be naturally inclined towards group participation. An important and new development was finding that such people may reconsider and compromise these aspects if they later found they needed greater support. Extending the invitation period could therefore be valuable, offering people who are initially unable or disinclined to attend the opportunity to take advantage of this rehabilitation support. Phase III CR is traditionally only offered in the early period, and invitation is generally 'one-off'.

Community-based CHD groups are not a timelimited opportunity, yet in practice an invitation was only made, if at all, in the early period. People could forget, or believe that a group was only for newly discharged patients. Although not all CR participants received a CHD group invitation or information, generally CR was the main source, as is supported by Bostock et al.'s (2007) study of participants. CR non-invitees were thereby doubly disadvantaged by also missing the primary opportunity for CHD group information. Addressing low awareness and negative attitudes among health service providers and policymakers towards these independent groups has previously been highlighted (Hildingh et al., 2000; Bostock et al., 2007). This study suggests that for some people this could address rehabilitation difficulties that are not currently addressed by other means.

Many interviewees who attended neither resource said they would have wished to attend both $\mathrm{CR}$ and CHD groups, viewing them as complementary. Commonly, these interviewees highlighted different types of needs, some of which they considered would be met by the 'medical model' offered by CR, for example, gaining confidence through clinician-supervised exercise, monitoring, and specialist advice. Alongside this, they desired support more akin to the 'social model' offered by $\mathrm{CHD}$ groups, such as ongoing informal interaction with others about managing day-to-day issues, and rebuilding their 'new life' beyond the early period. Some interviewees who had participated in CR shared this view, perceiving that CHD groups could have addressed needs not fully met by $\mathrm{CR}$, and support them in continuing rehabilitation activities.

Previous CHD group non-participant research focused on non-exercise groups (Hildingh and Fridlund, 2001; 2003). This study found some nonparticipants desired to attend CHD groups that incorporated exercise to regain and maintain fitness in a safe, tailored environment, which demonstrates a parallel with previous participant research (Gregory et al., 2006a; 2006b; Bostock et al., 2007). Physical health and regaining/ maintaining fitness were thereby of importance to many people who wished to participate in a CHD group as well as those who wished to attend CR. There was, however, an indication that some people with physical difficulties who had negative perceptions of exercise at $\mathrm{CR}$ as compulsory, rigidly organised, and standardised, perceived CHD groups more positively.

It has been suggested that the 'medical model' of health care can fail to meet patient needs, yet patients are reluctant to criticise health services (Staniszewska and Henderson, 2005). This study found low expectations, reticence about requesting support, and reluctance to criticise poor followup care. However, rather than negative perceptions regarding the 'medical model' of provision at CR, this related either to an absence of rehabilitation support of all kinds, or of the 'social model' type of support provided by CHD groups.

Other studies identify informal support from family and friends as an important influence upon non-participation (Hildingh and Fridlund, 2001; Jones et al., 2007), even if the form and process were not always clear. Specifically, this study found that lack of encouragement from 'significant others' could be a compounding factor in non-participation, sometimes having substantial weight. Conversely, informal information and recommendations from people they knew encouraged some interviewees to consider attending a post-MI resource. This influence is well established in the literature on illness experience (Freidson, 1970), but is new regarding CR and CHD group non-participants. This study found 'significant 
others' post-MI needs had generally been poorly met. Professionals had rarely identified their difficulties and referral to support resources was rare. This is seen in broader CHD studies (Svedlund and Axelsson, 2000; Tapp, 2004), although this study shows that in the specific context of nonparticipation and the absence of support for the post-infarct person, this could undermine their role as rehabilitation supporters as well as damage their personal well-being.

Although CR and CHD groups do not seem to fit the needs and perspectives of some people in categories one and two, these people have unmet needs. Few who received the 'Heart Manual' did not identify difficulties or issues on which more support would have been appreciated. Addressing primary and secondary care gaps will address some issues, but others require specific and tailored rehabilitation support interventions putting into practice the personalisation and selfmanagement policy agenda advocated for longterm conditions (Scottish Government, 2007; Colin-Thomé et al., 2009). There may also be people in categories two and three whose barrier issues prove insurmountable, and for these people it may be worth exploring how home-based support may be enhanced. One particular area suggested by this study could be online or telephone social networking, to address isolation and provide a means for learning and receiving support from others in similar circumstances. This model has proven successful regarding other conditions (Davison et al., 2000). Referral to professional specialist support, for example, regarding cognitive problems and employability, is also necessary. Such approaches are advocated in Redfern and Briffa's (2011) recent review; yet, where this study differs is in suggesting that while effective secondary prevention alternative models are required for some people, better access, availability, information, and encouragement for CR and CHD groups would enable many who otherwise become non-participants, to have their rehabilitation needs met.

\section{Conclusion}

$\mathrm{CR}$ and CHD group non-participation was a 'missed opportunity' for many people who experienced infarct and their family members and was linked to rehabilitation difficulties. Unmet needs were apparent even among people who had received a home-based rehabilitation resource, suggesting that this may not fully meet the needs of some people and families. This study strengthens previous evidence to suggest that enhancing existing CHD rehabilitation support resources and developing the linkages between them, staff, patients and their families, could be an effective, cost-efficient, and feasible way to achieve CHD goals.

\section{Acknowledgements}

Thanks are due to all those who participated in the study, the NHS staff who assisted with access to patient databases, and the General Practitioners who sent out questionnaires and information to potential participants. The research was assisted by financial support from the following institutions: The College of Medicine and Veterinary Medicine, The University of Edinburgh (PhD scholarship); The Royal College of General Practitioners Scientific Foundation Board; and The University of Edinburgh Small Grant Fund. The authors have no conflict of interest to declare.

\section{References}

Asch, D.A., Jedrziewski, M.K. and Christakis, N.A. 1997: Response rates to mail surveys published in medical journals. Journal of Clinical Epidemiology 50, 1129-36.

Beswick, A.D., Rees, K., Griebsch, I., Taylor, F.C., Burke, M., West, R.R., Victory, J., Brown, J., Taylor, R.S. and Ebrahim, S. 2004: Provision, uptake and cost of cardiac rehabilitation programme, improving services to underrepresented groups. Health Technology Assessment 8, iii-iv, ix-x, 1-152.

Bethell, H.J., Evans, J.A., Turner, S.C. and Lewin, R.J. 2007: The rise and fall of cardiac rehabilitation in the United Kingdom since 1998. Journal of Public Health 29, 57-61.

Blaxter, M. 2004: Health. Cambridge: Polity Press.

Bostock, Y., Gregory, S., Hanna, L. and McKinstry, B. 2007: CHD Support Groups in Scotland: a survey of the views of members and facilitators. Edinburgh: RUHBC, University of Edinburgh.

Bury, M. 1991: The sociology of chronic illness, a review of research and prospects. Sociology of Health and Illness 13, 451-68.

Campbell, N.C., Thain, J., Deans, H.G., Ritchie, L.D., Rawles, J.M. and Squair, J.L. 1998: Secondary prevention clinics for coronary heart disease: randomised trial of effect on health. British Medical Journal 316, 1434-37.

Primary Health Care Research \& Development 2012; 13: 30-41 
Charlton, G.S. and Barrow, C.J. 2002: Coping and self-help group membership in Parkinson's disease, an exploratory qualitative study. Health and Social Care in the Community 10, 472-78.

Clark, A.M. 2003: "It's like an explosion in your life...", lay perspectives on stress and myocardial infarction. Journal of Clinical Nursing 12, 544-53.

Clark, A.M., Barbour, R.S. and McIntyre, P.D. 2002: Preparing for change in the secondary prevention of coronary heart disease, a qualitative evaluation of cardiac rehabilitation within a region of Scotland. Journal of Advanced Nursing 39, 589-98.

Clark, A.M., Hartling, L., Vandermeer, B. and McAlister, F.A. 2005: Meta-analysis, secondary prevention programs for patients with coronary artery disease. Annals of Internal Medicine 143, 659-72.

Colin-Thomé, D., Collins, A., Eaton, S., Morton, T. and Roberts, S. 2009: Developing primary and community care based personalised care plans with people with long term conditions. In Paine, L., editor, 2009: integrated care. London: Sovereign Publications.

Cooper, A.F., Jackson, G., Weinman, J. and Horne, R. 2002: Factors associated with cardiac rehabilitation attendance: a systematic review of the literature. Clinical Rehabilitation $16,541-52$.

Dalal, H.M. and Evans, P.H. 2003: Achieving national service framework standards for cardiac rehabilitation and secondary prevention. British Medical Journal 326, 481-84.

Davison, K.P., Pennebaker, J.W. and Dickerson, S.S. 2000: Who talks? The social psychology of illness support groups. American Psychology 55, 205-17.

Dinnes, J., Kleijnen, J., Leitner, M. and Thompson, D. 1999: Cardiac rehabilitation. Quality in Health Care 8, 65-71.

Ebrahim, S. and Davey-Smith, G. 1997: A systematic review and meta-analysis of randomised controlled trials of health promotion for prevention of coronary heart disease in adults. British Medical Journal 314, 1666-67.

Finlay, L. 2003: The reflexive journey: mapping multiple routes. In Finlay, L., Gough, B., editors, Reflexivity. Oxford: Blackwell.

Freidson, E. 1970: Profession of medicine: a study in the sociology of applied knowledge. New York: Dodd, Mead and Co.

Gregory, S., Backett-Milburn, K. and Bostock, Y. 2005: Recovery from and management of coronary heart disease, an exploratory study of patients' views and experiences. Working Paper 2. Research Unit in Health, Behaviour and Change, The University of Edinburgh.

Gregory, S., Hanna, L. and McKinstry, B. 2006a: Coronary heart disease (CHD) support groups: their role and value from the perspectives of members and facilitators. Research Unit in Health, Behaviour and Change, The University of Edinburgh.

Gregory, S., Bostock, Y. and Backett-Milburn, K. 2006b: Recovering from a heart attack, a qualitative study into lay experiences and the struggle to make lifestyle changes. Family Practice 23, 220-25.

Primary Health Care Research \& Development 2012; 13: 30-41
Hagan, N.A., Botti, M.A. and Watts, R.J. 2007: Financial, family and social factors impacting on $\mathrm{CR}$ attendance. Heart and Lung 36, 105-13.

Hildingh, C. and Fridlund, B. 2001: Patient participation in peer support groups after a cardiac event. British Journal of Nursing 10, 1357-63.

Hildingh, C. and Fridlund, B. 2003: Participation in peer support groups after a cardiac event: a 12-month follow-up. Rehabilitation Nursing 28, 123-28.

Hildingh, C., Fridlund, B. and Segesten, K. 2000: Self-help groups as a support strategy in nursing, a case study. Rehabilitation Nursing 25, 100-04.

Jackson, A.M., Gregory, S. and McKinstry, B. 2009: Self-help groups for patients with coronary heart disease as a resource for rehabilitation and secondary prevention what is the evidence? Heart and Lung 38, 192-200.

James, A. and Hockey, J. 2006: Embodying health identities. Basingstoke: Palgrave Macmillan.

Jepson, R.G., Hewison, J., Thompson, A.G. and Weller, D. 2005: How should we measure informed choice? The case of cancer screening. Journal of Medical Ethics 31, 192-96.

Jolliffe, J.A., Rees, K., Taylor, R.S., Thompson, D., Oldridge, N. and Ebrahim, S. 2001: Exercise-based rehabilitation for coronary heart disease. Cochrane Database of Systematic Reviews 1, CD001800.

Jones, M., Jolly, K., Raftery, J., Lip, G.Y. and Greenfield, S., BRUM Steering Committee. 2007: 'DNA' may not mean 'did not participate': a qualitative study of reasons for non-adherence at home- and centre-based cardiac rehabilitation. Family Practice 24, 343-57.

Mackay, J., Mensah, S. and Greenlund, K. 2004: The atlas of heart disease and stroke. Geneva: World Health Organisation.

Mason, J. 1996: Qualitative researching. Thousand Oaks: Sage.

Petersen, S., Rayner, M. and Peto, V. 2003: Coronary heart disease statistics. London: BHF; http://www.heartstats.org/ datapage.

Pope, C. and Mays, N. 2000 editor, Qualitative research in health care, second edition. Boston, MA: Jones and Bartlett.

Redfern, J. and Briffa, T. 2011: Cardiac rehabilitation moving forward with new models of care. Physical Therapy Reviews 16, 31-8(8).

Richards, N. and Coulter, A. 2007: Is the NHS becoming more patient-centred? Trends from the national surveys of NHS patients in England, 2002-07. Oxford: Picker Institute Europe.

Roebuck, A., Furze, G. and Thompson, D.R. 2001: Healthrelated quality of life after MI: an interview study. Journal of Advanced Nursing 34, 787-94.

Sandelowski, M. 1995: Sample size in qualitative research. Research Nursing and Health 18, 179-83.

Scottish Intercollegiate Guidelines Network. 2002: Cardiac Rehabilitation. Guideline No. 57. Edinburgh: SIGN.

Scottish Government. 2007: Better health, better care: action plan. Edinburgh: The Scottish Government.

Seale, C. and Kelly, M. 1998: Researching society and culture. London: Sage Publications. 
Staniszewska, S.H. and Henderson, L. 2005: Patients' evaluations of the quality of care: influencing factors and the importance of engagement. Journal of Advanced Nursing 49, 530-37.

Svedlund, M. and Axelsson, I. 2000: Acute myocardial infarction in middle-aged women, narrations from the patients and their partners during rehabilitation. Intensive Critical Care Nursing 16, 256-65.

Tapp, D.M. 2004: Dilemmas of family support during cardiac recovery: nagging as a gesture of support. Western Journal of Nursing Research 26, 561-80.

Taylor, R.S., Dalal, H.M., Jolly, K., Moxham, T. and Zawada, A. 2010: Home-based versus centre-based cardiac rehabilitation. Cochrane Database of Systematic Reviews 20, CD007130.

Thompson, D.R. and de Bono, D.P. 1999: How valuable is cardiac rehabilitation and who should get it? Heart 82, 545-46.
Thompson, D.R. and Lewin, R.J. 2000: Coronary disease. Management of the post-myocardial infarction patient: rehabilitation and cardiac neurosis. Heart 84, 101-5.

Wheatley, E.A. 2006: Bodies at risk: an ethnography of heart disease. Ashgate: Burlington.

Wiles, R. and Kinmonth, A. 2001: Patients perceptions of their heart attack and recovery, the influence of epidemiological 'evidence' and personal experience. Social Science and Medicine 46, 1477-486.

Wingham, J., Dalal, H.M., Sweeney, K.G. and Evans, P.H. 2006: Listening to patients: choice in cardiac rehabilitation. European Journal of Cardiovascular Nursing 5, 289-94.

Ziebland, S. and McPherson, A. 2006: Making sense of qualitative data analysis: an introduction with illustrations from DIPEx (personal experiences of health and illness). Medical Education 40, 405-14. 